\title{
Education for Sustainability Curriculum and Pedagogy in Higher Education Institution: Using Complex Adaptive System as a Framework
}

\author{
Siti Nur Diyana Mahmud1, Zaizul Abdul Rahman² \\ ${ }^{1}$ Faculty of Education, Universiti Kebangsaan Malaysia, Bangi, Malaysia \\ ${ }^{2}$ Faculty of Islamic Studies, Universiti Kebangsaan Malaysia, Bangi, Malaysia \\ Email: diyana@ukm.edu.my, zaizul@ukm.edu.my
}

How to cite this paper: Mahmud, S. N. D., \& Rahman, Z. A. (2018). Education for Sustainability Curriculum and Pedagogy in Higher Education Institution: Using Complex Adaptive System as a Framework. Creative Education, 9, 2627-2646. https://doi.org/10.4236/ce.2018.915198

Received: October 13, 2018

Accepted: November 23, 2018

Published: November 26, 2018

Copyright $\odot 2018$ by authors and Scientific Research Publishing Inc. This work is licensed under the Creative Commons Attribution International License (CC BY 4.0).

http://creativecommons.org/licenses/by/4.0/

\begin{abstract}
This paper presents the study on the interaction between Education for Sustainability (EfS) curriculum and pedagogy with EfS systems structure. Complex Adaptive System (CAS) was used as a framework in analysing the data. This study identified the EfS curriculum and pedagogy has being stimulated by socio-cultural factors, local sustainability issues and global sustainability agenda.
\end{abstract}

\section{Keywords}

Systems Thinking, Education for Sustainable Development, Higher Education, Curriculum, Pedagogy

\section{Introduction}

In 2002, the United Nations (UN) declared the period 2005-2014 as the Decade of Education for Sustainable Development (DESD). Education for Sustainable Development or Education for Sustainability (EfS) is a process that develops people's awareness, competence, attitudes and values, enabling them to be effectively involved in sustainable development at local, national and international levels, and helping them to work towards a more equitable and sustainable future. In particular, it enables people to integrate social and cultural considerations with environmental and economic decision-making (Huckle \& Sterling, 1996). The aims of Education for Sustainable Development (ESD) suggested by UNESCO are to help people to "develop the attitudes, skills, and knowledge to 
make informed decisions for the benefit of themselves and others, now and in the future, and to act upon these decisions" (UNESCO, 2017: p. 13). Other studies (Rowe, 2002; Sterling \& Thomas, 2006; Sipos, Battisti, \& Grimm, 2008; Segalàs, Ferrer-Balas, Svanström, Lundqvist, \& Mulder, 2009; Wiek, Withycombe, \& Redman, 2011) have suggested that Education for Sustainability (EfS) goals are to generate students' competence in systemic thinking, critical thinking, able to work within trans-disciplinary field, and to cultivate values that are consistent with sustainability paradigms. Despite these lofty aspirations and more than 30 years of the official introduction of the term sustainable development in the Brundtland Report (1987), the impact of EfS is unclear and inconclusive. This raises important questions that warrant exploration. Is higher education guilty of ineffectively doing the same thing over and over again? And is it time to step back and reflect on the efficacy of EfS strategies to make sure they are producing the intended results?

In this paper, the finding from the study in one Malaysian case university will be presented. Since the concept of sustainability was raised in Agenda 21, the Malaysian government has promoted holistic development. Malaysia began to implement proactive policies and strategies at different levels from the 7th Malaysia Plan (Malaysia, 1996) onwards. More than 60 years ago since independence, Malaysia has undergone rapid economic growth. While the development of nation over the last six decades is impressive, the rapid pace of change has shown its' detrimental effects on the natural environment. In this paper, the next sections will present the current Education for Sustainability in Malaysian Case University, the theoretical framework Complex Adaptive System, the methodology, and findings and discussion.

\section{Education for Sustainability in Malaysian Case University}

While sustainability has become a 'buzzword' in Malaysian higher education institutions there are no comprehensive studies that investigate the interaction between EfS curriculum and pedagogy with EfS system structures. Previous studies of sustainability in Malaysian HEIs focused on separated dimensions of sustainability in HEI (e.g. Darus et al., 2009; Derahim, Hashim, Ali, \& Derahim, 2011; Abdulrazak \& Ahmad, 2014; Omar et al., 2009) rather than on multiple and integrated dimensions. To understand the EfS enactment in this study, it requires more than simply an examination of the EfS curriculum and pedagogy. To grasp why and how the EfS is implemented by the participants, the study needs to consider the contexts and the structure of the system in which it was created and implemented (Lattuca \& Stark, 2009). In line with this, Bateson (1987) argued that learning is about the relationship between humans or the organisations and their biophysical environment.

Systems structure is the next level of explanation, which reveals how trends and patterns relate to and affect one another. This represents a much deeper level of thinking that can demonstrate how the interaction between various factors 
gives rise to the observable outcomes. The uptake and implementation of EfS in the HEI curriculum is slow, due to barriers such as lecturer understanding and attitude (Dawe, Jucker, \& Martin, 2005), the discipline-focused nature of many academics' work (Moore, 2005), the perceived irrelevance of EfS to some disciplines, and crowded existing curricula (Dawe, Jucker, \& Martin, 2005). To understand the interaction and patterns at the systems structure level, CAS was applied as the framework for the analytic process. A detailed explanation of how CAS is being used as a framework in this study will be discussed in the next section.

Data from three established high-ranking public research universities in Malaysia indicated that university sustainability programs focus mainly on physical campus greening, green procurement and research on green technology (Omar et al., 2009). This mirrors findings from England where the strategic review of EfS by the Higher Education Funding Council for England (2008) identified, HEIs focused on campus greening rather than substantive reform of pedagogy and curriculum. According to Sydow (2012), sustainability in higher education typically refers to greening the campus and attempts to reduce the university's ecological footprint. A study by Elfithri et al. (2017) on a decade of sustainable campus programmes in the Malaysian case University found that the programmes are not properly planned or coordinated. Many programs are condensed into a short period of time. Elfithri et al. (2017) also found that there are unequal activities among sustainable research groups with only one of the three groups (i.e. Sustainable Ecosystem Management Research Group) still active. The Sustainable Ecosystem Management Research Group focuses on conservation and management of water, energy, and waste resources. Unfortunately, EfS is not a priority for even this active research group so the achievement of the sustainable development goals (UNESCO, 2017) seems even more remote. Despite 10 years of sustainability initiatives in the Malaysian case University, Derahim et al.'s (2011) and Er Ah Choi et al. (2017) identified critical gaps and weaknesses remained in the knowledge and awareness of students and staff which poses major challenges to Malaysian case University.

Education for sustainability literature argues that to implement EfS, requires a change of fundamental epistemology in educational thinking, practice and culture (Bacon et al., 2011; Barth, 2013; Pappas, 2012; Sterling, 2004). The present study took up the clear requirement for a systems approach that addresses the interconnection between dimensions of the problem and provides an integrated way of seeing and thinking about the problem. In this case, the systems approach entails documenting the interconnection between the organisational structures and policies of the Malaysian case University; as well as relevant aspects of the social and political context in Malaysia more generally. Such an analysis is designed to provide an understanding of the wicked educational problem where EfS does not produce the intended result. 


\section{Complex Adaptive Systems}

A CAS is being utilised as the analytical framework to understand the interaction of EfS curriculum and pedagogy, with EfS systems structure levels. Many natural systems (e.g., immune systems, ecologies, societies) are characterized by complex behaviours that emerge as a result of often nonlinear interactions among a large number of component systems at different levels of organisation. These systems, which are dynamic systems with the ability to adapt in and evolve with a changing environment, have recently become known as Complex Adaptive System (CAS). It is important to be aware that there is no separation between a system and its environment because all systems exist within their own environment and they are also part of that environment. When the system changes, it changes its environment, and as the environment changes, the system needs to change again. Within such a context, change needs to be seen in terms of co-evolution with all other related systems, rather than as adaptation to a separate and distinct environment. According to CAS theory, the environment and the system co-evolve (Holland, 1992); changes in the system change the environment, which requires the system to change again to fit with the new changed environment.

In the CAS framework, sensitivity to the external environment reflects the idea that organisms and their environments evolve together. Sensitivity to external events and the flexibility to adapt in a timely manner are key success factors for organisations seeking to improve sustainability under such conditions (Holland, 1992; Karwowski, 2012). The process of interaction between a system and its environment involves selection and temporality: selection, because the system has to recognise which phenomena, out of a range, are to be responded to; and temporality, because a process of change takes time.

\section{Methodology}

The systems theory approach to understanding sustainability in policy and practice requires intensive description and insight into a specific context. The intent of this study is to describe and analyse the systemic patterns that emerge at the Malaysian case university EfS system structures, and EfS curriculum and pedagogy interact. Such a purpose suggests a case study design since, according to Yin (2003) it is the recommended approach when: 1) the focus of the study is to answer "how" and "why" questions; 2) the behaviour and interpretations of those involved in the study cannot be manipulated; and 3) the contextual conditions are relevant to the phenomenon under study. For these reasons, the case study design was chosen as the research design. The choice of the University was based on accessibility for the researcher but also it was a "telling case" since it has a particular mission in Malaysia as the University concerned with national culture and heritage. So understanding the sustainability policies and practices in this context has potential to reveal what a distinctive and nuanced Malaysian approach to EfS might entail. 
The data used in this paper were from the series of interviews with lecturers who teach sustainability related courses (i.e.: L1, L2, L3, L4, L5, and L6). All the lecturer participants are female lecturers from diverse fields (i.e. anthropology, education, applied biology, engineering, and general study). Meanwhile, focus group interviews were conducted with three groups of students (Focus group 1, 2 , and 3) enrolled in the selected sustainability courses (Course 1, 2, and 3). The participants in the three focus groups were volunteers from each course. The data also consist of analysis of the course structure form selected sustainability courses, observation in the three sustainability courses and analysis of documents. The characteristic of the participants in the focus group 1,2, and 3 is shown in Table 1.

Meanwhile, for the observation in sustainability related courses teach by L2 (teach Course 1), L1 (teach Course 2) and L4 (teach Course 3), the criteria that been observed are; a). Content covered during the lesson, $b$ ). Types of activities implemented during the lesson, c) Role of the lecturer during the lesson, d). Role of the student during the lesson, and e). Interaction between the lecturer and students. For focus group interviews with the students enrolled in the Course 1 , 2 , and 3, the questions concerning EfS learning and teaching were following the dynamic flow of topic communicated during the focus group interviews. The questions were not strictly structured for focus group interviews. The data in this study were analysed through thematic analysis.

\section{Findings}

This paper will present and discuss the findings of the interaction between EfS systems structure, and EfS curriculum and pedagogies. Perceived EfS curriculum and pedagogies data were derived from the interviews with the lecturers, student participants' focus group interviews, class observations, and course structure documents. EfS systems structure was identified from lecturer's interviews, student participants' focus group interviews, class observations, course structure documents, the university mission statement, the university sustainable campus mission and objective statements, the university sustainable charter, reports available on sustainability programmes at the university from 2008-2017, sustainability research projects documented by the University Centre for Research and Instrumentation, the university sustainability-related Credited Co-curricular Activities, sustainability competency courses and elective courses offered to the students at the Malaysian case University, and Green Metric World University Sustainability Ranking 2014-2107 audit reports.

In this paper, the discussion of the interaction between EfS systems structure and EfS curriculum and pedagogies are divided into five sections: 1) socio-cultural influence on EfS learning and teaching, 2) religion interaction on EfS learning and teaching, 3) local sustainability issues influence on EfS teaching, 4) global influence on EfS teaching; and 5) educator's factors influence on EfS teaching. 
Table 1. Focus group description.

\begin{tabular}{ll}
\hline Focus group & Description \\
\hline Focus group 1 & $\begin{array}{l}\text { Focus group 1 consists of six students. Participants were Malay and } \\
\text { Female Muslim students. This group is a mix of students from } \\
\text { Anthropology, Development Sciences and Geography programs. }\end{array}$ \\
& $\begin{array}{l}\text { Focus group 2 consists of five students. This group of participants } \\
\text { was a mix of genders, races, religions and discipline background. } \\
\text { Focus group 2 }\end{array}$ \\
& $\begin{array}{l}\text { The discipline background ranged from science and technology, } \\
\text { engineering, law and social sciences. }\end{array}$ \\
& $\begin{array}{l}\text { Focus group 3 consists of five students. Participants in this group } \\
\text { Fere Malay and Muslim and came from Biology program. This } \\
\text { group had a mix of genders. }\end{array}$ \\
\hline
\end{tabular}

\subsection{Socio-Cultural Influence on EfS Learning and Teaching}

Many voices, including UNESCO, the World Summit on Sustainable Development, and researchers, are calling for the inclusion of socio-cultural considerations into the sustainable development model (UCLG, 2011). The socio-cultural issues can shape what people mean by development and determine how people act in the world. In this section, the findings of socio-cultural influence on EfS learning and teaching are presented and discussed.

In Malaysia context, the power distant dimension is very high (Hofstede Insight, 2017). Power distance is a term that describes how people view power relationships of superior and subordinate relationships between people. Individuals in cultures demonstrating a high power distance are very deferential to figures of authority and generally accept an unequal distribution of power. The high power distance was also reflected in learning and teaching in this study. According to Hofstede (1986), power distance has a strong impact on learning in the context of a student-lecturer relationship. This leads to passive learning, where the students are hesitant about being critical towards what the lecturer said, and asking questions in a class. L1, during her interview, raised her concern about passive culture adopted by the Malaysian students in her class. She stated:

I will deliver a lecture to teach about "sustainability". Nevertheless, it is difficult to encourage the students to ask questions during the lecture. I think you are familiar with the students culture in Malaysia. To overcome the problem, I pose a question to give them an issue, so they have to give their own opinion (L1's interview).

Ll's concern about her students' participation during the class had driven her to move from a traditional lecture to a more participatory learning. Her approach is that she is still guiding the discussion with students instead of opening a discussion which is fully led by the students. Her approach in teaching could be observed during Course 2 class observation. L1's view on EfS purpose interaction with EfS curriculum and pedagogies in a context where "face-saving" culture is dominant, the students usually avoid asking questions until they fully understand the whole lesson to prevent being seen as unintelligent (Hoffstaedter, 
2011). In the same vein, L3 argued that her students prefer to ask questions one-to-one after the class rather than during the class. She stated, "If they have any question, usually they will come to ask the lecturer after the class dismissed. Nevertheless, they always said they understand the lesson during class (laugh)" (L3's interview). Furthermore, in a face-saving culture, they tend to be less critical towards the teacher, to show their respect to the teacher (Hoffstaedter, 2011). In addition, L4 also noted the passiveness of the students in her class. She stated, "I need to probe them with a lot of questions to encourage them to speak in a class. Otherwise, they will be silent. It is difficult to identify whether they understand the lesson or not' (L4's interview). The passiveness of the students also appeared during the class observations. During class observation in Courses 1, 2, and 3, it was noticed the students were busy taking down their lecture notes. It appeared that the students were passively absorbing information presented by the lecturers, despite research indicated that didactic, teacher-centered education results in reduced cognitive and behavioural outcomes (Segalàs, et al., 2009; Redman, 2013). Nevertheless, in a collectivist cultural context, this type of behaviour from the students is considered as appropriate and a norm when they are in the classroom. The lecturers in many Asian cultures are given the status of guru, who are responsible to learners in their search for knowledge and who are perceived by the students as the primary source of knowledge in the classroom (Sulaiman, 2013). The stream of knowledge is transmitted in a one-way direction from lecturers to students. This finding is consistent with the study conducted by Yen et al. (2005) that reported a great number of Malaysian students are passive and spoon-fed learners, who rely heavily on rote learning. Nevertheless, despite the students' noticeable passiveness in the class, the student participants actually preferred active learning modes that emphasize hands-on and outdoor learning as they stated during focus group interviews. While the students act passively and adhere to the local cultural norms for compliance, they prefer learning actively in the field instead of didactic learning in the classroom.

"Collectivism" is another important socio-cultural feature. In collectivist societies, conflict is avoided as it is important to form mutual opinions with other members of the society. In this study, L3 was aware of the reason that her students were not expressing their individual opinions when they were doing the case study in a group. The written report completed by the students merely included factual information. Thus, she asked them to write their individual reflections. She stated:

We also embed the concept of environment in the learning process. For example, by giving students tasks based on places or place-based or evaluation on the surrounding area. I will ask the students to do the case study and report in a group, but they need to write an individual reflection of what they have learnt from the case study. Sometimes, they just write the factual information in the report without critically discussing. It is difficult to 'hear their voice' in the report. Thus, I asked them to write an individual reflection. They can write how 
they feel, and what they think in the reflection (L3's interview).

Based on L3's excerpt, it showed that she deliberately adopted various ways to counter what she perceived as a sociocultural impediment to deeper understanding. She focused on the individual understanding through reflective writing about feelings and thoughts. Individual understanding is not the most important in collectivism. Nevertheless, the mutual consensus is more appreciated. Therefore, L3's strategy is to work across this dilemma.

L2 also commented on the socio-cultural influence on the sustainable behaviour and EfS learning. The notion of collectivism in her interview concerned of how the society and students value belonging to a group. She stated:

Social value has some impacts. In Malaysia nowadays, the values from social surrounding are slowly gaining some impacts on human behaviour towards the environment. They started considering the community pressure towards protecting the environment. Especially in urban areas, the socio-culture started to transform towards more environmental friendly. The similar situation is slowly gaining popularity in the university campus. Don't be surprised if the students said they do environmental friendly behaviour not for the sake of taking care the environment, but for their social image, and follow their peers' actions. Thus, when we are planning educational programs for EfS, we need to consider on how to make the program popular and interesting for the students (L2's interview).

L2's reflection contrasts an authentic commitment to the environment with the spread and uptake of social norms regarding littering and other environmental behaviours. She suggested that the shift of the students towards more responsible behaviours and interest in sustainability is related to group conformity and popularity. Thus, she suggested EfS programs should be able to attract the students by making it more exciting. When many students are attracted to involve in EfS programs, it will create social norms at the university and more students will join the programs in the future.

L4 argued that her students are strategic institutional learners as they are likely to carry out the activity only if it has marks for their course. L4 noted:

It is hard to find volunteers to do sustainability works. The culture here is, everything needs to be enforced, through a top-down management instruction. Same situation with the students. You need to give marks or credit, or make it compulsory, for every task you asked them to do. Otherwise, it is difficult to find students who volunteer to do it (L4's interview).

In highly collective societies, a reward obtained at the end of the program is highly appreciated (Hofstede Insight, 2017). Thus, it is predictable when L4 observed that her students were reluctant to participate in EfS activity if there was no reward offered to them at the end of the activity. In addition, based on the analysis of sustainability programs at the university, an eco-volunteer activity which started in 2011, became a credited co-curricular activity in 2015. As a result, more students began to participate in such activity. 
To summarise, socio-cultural factors were mentioned by lecturers as the deterrents to the EfS enactment in their courses. Thus, they took reformative actions to overcome the problems. The lecturers' reflections on the socio-cultural context followed by a modification of their teaching approach are considered as double-loop learning. From a CAS perspective, this double-loop reformative response by the lecturers indicated a co-adaptation between lecturers' teaching approach and students' socio-cultural context.

\subsection{Religion Interaction with EfS Learning and Teaching}

In the previous section, the socio-cultural influences on EfS teaching and learning were discussed. According to Hawkes (2001), culture is "not limited to arts and heritage, but encompasses the whole complex of distinctive spiritual, material, intellectual and emotional features that characterize a society or social group" (p.35). Thus, in this study, the inclusion of a religious-spiritual dimension provided an insight into the influence of religion on EfS learning and teaching. During the focus group interviews with the students and semi-structured interviews with lecturers, the question was "What do you think about religious influence on Education for Sustainability?".

Students in Focus groups 1, 2, and 3 argued that religion is the foundation for sustainable behaviour as they equate it to "good behaviour". According to the students, every religion exhorts humans to do good deeds, and they perceived sustainable behaviour as good behaviour. They stated:

Students $1 F$ : Everything starts with religion. I mean, if the person has a good basis of religion, he or she will have good sustainable behaviour.

Student 1B: Because all religions promote good behaviour.

Student $1 D$ : Yes, religion is important.

(Focus group 1 interview)

A similar notion of religions' general influence on sustainability behaviour was also mentioned by students in Focus group 2. They stated:

Student 2D: Yes, religion has an influence on sustainability. Our religion teaches us to be moderate in everything that we do.

Student 2E: Every religion teaches us to do a good thing.

Student 2B: Religion also has an influence on ethics in science and technology. In Malaysia, we depend on religious teaching on what we can do, and what we can't do.

Student 2A: From the legal point of view, yes, it does. Religion and belief have an influence on sustainability. One of the components in the philosophy of law is natural law. In natural law, it is stated that there is a requirement to consider whether the law is valid or not valid via morality. Moral does get the sources from religious sources.

(Focus group 2 interview)

Students linked religion and other disciplines such as law (2A) or science and technology (2B) in explaining how religion might influence sustainability beha- 
viour. Both students $2 \mathrm{~A}$ and $2 \mathrm{~B}$ argued that religion is a source of moral inspiration. Nevertheless, they developed more layered arguments by integrating religious considerations into their degree studies.

Students in Focus group 3 also argued that religion influence on sustainability and student $3 \mathrm{~B}$ associated religion with their culture. This showed an integration of religion and culture is fairly simplified rather than articulated in depth and detailed. Thus, the question is how well the students have developed their knowledge regarding religion and sustainability.

Student $3 E$ : Yes, religion has an influence on sustainability.

Student 3 A: Of course religion has an influence on sustainability

Student $3 B$ : Religion is our culture.

(Focus group 3 interview)

Despite all three focus groups argued about religion influence on sustainability, they did not explain how religion has or might influence the EfS curriculum and pedagogy.

Stewardship has become the most common way eco-theologies have been speaking about the human relationship to the natural world in theological terms. Stewardship or Khalifah, positioned human beings in the role of trustee and custodian of the Earth. Thus, responsible for building the Earth and utilizing its resources with a sense of justice to oneself and to fellow mankind (Faruqi, 2007). The stewardship framed by Faruqi (2007) in fact omitted to mention the inherent interests of the more-than-human world. The stewardship is an anthropocentric perspective that places human interests and needs at the pinnacle of decision-making and can too easily be used to marginal the interest of the more-than-human world. In fact, the lecturers had different understandings of stewardship arising from Islamic teachings. For example, L4 asserted her belief on the significance of religious teachings about protecting the environment: " $I$ think religion and your belief are important in sustainability. In religion, it teaches us to protect by not doing a harmful thing to the biological resources" (L4's interview). L4's claim regarding religious doctrine protecting nature is consistent with the verse in the Quran (17:44) that mentioned humans should seek to protect and preserve the environment. By so doing, they protect God's creatures, which pray and praise God. On the other hand, the concept of stewardship as a privilege of human beings was mentioned in L6' interview. L6 conceptualised sustainability as closely related with Muslims' obligations: "Sustainability also has something to do with being a Muslim" (L6' interview). The concept of stewardship establishes obligations, grounding the relationships between human beings and other beings. Furthermore, she added: "In Islam, the Quran has stated about Allah does not want us to disturb whatever is in the environment' (L6' interview). She claimed that in Islamic theology, the actions that disturb the environment are prohibited. Nevertheless, how this prohibition can be interpreted and implemented in the modern industrialised world and consumerist society is not addressed. It suggests that this religious belief, sincere as it 
may be is not well connected or integrated with everyday life and actual behaviour.

On the other hand, religion was perceived as a weak determinant that can influence sustainable behaviour. L3 argued about the insignificance of religion in influencing sustainability and EfS. She stated:

To be honest, I don't think religion has anything to do with sustainability or EfS. There is no significant impact from a religious point of view on sustainability approach or practice despite we are being taught to be modest in usage or consumption in Islam, and also to protect our Earth (L3's interview).

L3 explicitly noted the lack of integration between Islamic beliefs and sustainability while highlighting the importance of modesty and protecting "our Earth". There is sense that Muslims are not following the teachings completely.

As stated by student 3B during the focus group interview, "In fact, religion can give significant influence. It is regarding whether we are truly a good follower or not a good one. We take it lightly, and we think it is not a big sin even if we littering the place." (Student 3B focus group interview). In the same vein, L1 also raised the question about whether the person is really following the teachings of the religion. She argued:

Of course as a Muslim, I believe Islamic teaching is always right about the environment. Every religion teaches about the good thing, but does the practitioner really do what the religion preaches? (L1's interview).

L2 and L5 viewed that religion has a least influence on sustainability as Muslims do not relate sustainable behaviour with Islamic teaching. She stated:

If I looked at my studies, from 2009 up to now in two different countries, the religious factor is least influential. Not because religion doesn't talk about the environment or does not have guidelines about the principle in the environment, but the problem is, people wouldn't relate environmental behaviour to religious factors. Rarely do they relate their environment behaviour towards the religion. Actually, the religious factor can be the best trigger towards environmental friendly behaviour and to be used in EfS if the religious is fully utilised by the followers (L2's interview).

L5 also agreed that religion had insignificant influence in society today. She mentioned, "Religion is important. Nevertheless, sometimes, people do not think that caring for nature is part of religion. This is probably due to the reason that the sustainability is not being stressed in Islamic education" (L5's interview). Student 3B, L3, L2, L1, and L5 argued that Islamic teaching promotes taking care of nature and living modestly and in harmony with the environment. Nevertheless, Muslims do not associate sustainable behaviour with Islamic teaching, and even if they do, they do not follow the teaching completely. Despite the Islamic revival in Malaysia during the late 1970s and early 1980s, Islam was increasingly co-opted into the government policy and public life (Hoffstaedter, 2011) regardless sustainability was not perceived as a necessity to be a good Muslim. As a conclusion, religion interaction with the EfS can be the source of 
moral inspiration and influence sustainability behaviour and EfS if such interaction is being fully utilised by the followers. Nevertheless, in reality, religion is insignificant to influence EfS as sustainability is not strongly associated with religious teaching in Malaysia.

\subsection{Local Sustainability Issues Influence on EfS Teaching}

The local context where the EfS is implemented has an important role. According to Rio Declaration, the EfS must be locally relevant and culturally appropriate.

In this study, the local sustainability issues interaction with EfS teaching can be classified as: 1) local sustainability issues as a stimulus to teach EfS, and 2) local sustainability issues as learning and teaching medium. L5, L1, and L2 provided a justification for incorporating EfS into the curriculum, by highlighting the rapidly changing environmental conditions with profound consequences for humanity. L5's (a lecturer in a general study institute) response to the question was, "With many environmental problems now, it is good if we can educate people" (L5's interview). In addition, L1 also raised the urgent concern about uncertainty in the sustainability crisis. She stated:

To me, it is very urgent. As you asked just now, when we mentioned this to those who are not pro-sustainability, they have other demanding issues. In my opinion, it is very important to incorporate sustainability issues into the curriculum in school, universities and colleges due to our situation now. You see, environmental problems become worse day by day. A few days ago, we came across the news about the mud flood in Cameron Highland. In the past, this is impossible to happen, but it is happening now due to the greediness of humans (L1's interview).

L1 justified the need to incorporate EfS into the curricula by providing a local example of the sustainability crisis. Furthermore, L2 argued for the urgency to implement EfS due to the worsening local environmental problems. She stated:

The environmental problem needs to be solved before it become more complicated. So, we need to implement Education for Sustainable Development effectively and start an action now. In the past, people produce different composition of rubbish. Nevertheless, since many people are using plastic and polystyrene, so now we have a lot of plastic and polystyrene rubbish, which are non-degradable. (L2's interview)

Local sustainability problems triggered a sense of urgency in L5, L1 and L2, causing them to argue that the EfS need to be implemented effectively to face the sustainability crisis. L1, L5, and L2 perceived EfS as an "instrument" with which to face the sustainability crisis. This is consistent with the societal expectation that the education should produce a responsible and informed citizen who understands how human activity impacts on the environment and what actions should be taken to mitigate the sustainability crisis (Stratton, 2015).

On the other hand, the lecturer participants also utilised local sustainability 
issues or problems as their teaching medium. They perceived that the EfS pedagogies are often place-based or local issue-based. They encouraged critical thinking, by analysing local contexts. L3 argued for using local case studies in her teaching approach. She stated:

We can embed the real world local sustainability problem in the learning process. For example, designing tasks for the students based on places or evaluation in the surrounding areas. Recently, I instructed the students to do a case study in the Kuala Lumpur by looking at the sustainable aspect. The students investigated whether the sustainable concept had been embedded in the provision of housing, the facilities and so on. Moreover, after conducting the case study, we did some reflections with the students. As you know, Kuala Lumpur is very condensed, and development in that area is very fast. This led to some sustainability problems in the area. I think the students can learn a lot from the Kuala Lumpur case (L3's interview).

Local cases of sustainability problems have the potential to establish relevance for the students. Furthermore, problem-based learning (PBL) was used in Course 1. According to L2 who teaches this course, the students were required to do a PBL research project by presenting local sustainability problems that were related to the topics. The students needed to analyse local sustainability issues originating from value differences by constructing a questionnaire and/or interview guide for a research project, and presenting the research findings in verbal and written forms. In the same vein, local sustainability issues were being utilised as students' research project in Course 3. The course outline stated:

Students will be given the opportunity to critically assess sustainability issues on multiple scales and disciplinary scopes in problem-oriented and solution-driven research projects (Course 3-course outline).

Sustainability issues in the campus also have great potentials for EfS learning. L5 presented the campus sustainability issues to her students by taking her students for a walk around campus to observe pollution in waterways. This approach was recommended by Redman (2013), who argued real-world explorations present authentic investigations of intersecting components while avoiding the over-simplifications found in hypothetical scenarios.

As a conclusion, local sustainability problems were perceived by the lecturer participants as stimuli that influence EfS enactment. Furthermore, local sustainability issues were being utilised as an effective medium as they have potential to create relevance for the students.

\subsection{Global Influence on EfS Curriculum and Pedagogy}

Impact of globalisation on each country is different due to the different history, traditions, cultures, resources and priorities in the countries. The process of globalisation has a strong impact on education as the events that happen on a global scale also are able to influence national education systems.

Global sustainability initiatives influence the university sustainability policy in 
explicit and tangible ways. Nevertheless, global sustainability initiatives have only weak effects on EfS curriculum in an intangible way. In Courses 1, 2, and 3, globalisation is focused in only one of the topics covered in the courses. In Course 1, the topic is "Environment, politics and globalisation". In Course 2, the topic is "Contemporary Global Environmental Problems \& Governance", whereas in Course 3, the topic is "Global pattern of conservation". The global sustainability agenda constituted less than $10 \%$ of the overall content. Furthermore, during the focus group interviews, the student participants did not acknowledge the global sustainability issues. They excluded global sustainability issues, such as global warming, as the priority agenda in sustainable development. In fact, they actively stated that they did not see it as a priority compared to the local sustainability issues.

On the other hand, according to L4, in biology conservation field, they need to follow international standard. Thus, the exposure to the global trend is crucial. She stated:

For biological diversity, we always follow the international declaration of biodiversity that Malaysia has signed. Moreover, we must follow the global rules and regulation. We don't enact the rules by ourselves. That's why we need to expose the students to the global regulations and trends in biodiversity. It is important. (L4's interview).

In the same vein, Lina argued that there is a global influence on her field i.e. the facility and building management. She stated, "In my field, we have the global index of green building" (L3's interview).

On the other hand, the global influence on EfS teaching was not obvious in this study. The reason is that the lecturer participants tend to use local sustainability issues in their teachings. Furthermore, according to L3, she argued that global influence only affects the general sustainability practices but does not impact much on the education. She stated, "I think, to be honest, global sustainability agenda has an influence only on some sustainability practices and researches in Malaysia, but not on the sustainability in education" (L3's interview). This is due to the reason that not all global sustainability initiatives are appropriate for the local context. As argued by L6, "Globalisation has influenced us. For example, you are studying at an overseas university, and bring back what is good or maybe bad to implement it in Malaysia. Therefore, we need to think of which approach is suitable for our local context. Some western approaches might be not suitable." (L6' interview). L6' claim is consistent with Kopnina and Meijers' (2014) argument about not all the EfS practice examples in western universities are universally applicable. There are countries where EfS is practised with great differences in their socio-political priorities, and in their political, ecological, and economic factors.

\subsection{Educator's Factors Influence on EfS Teaching}

In this study, the educator's factors that were perceived as important for EfS are: 
1) educator's knowledge on the sustainability topic, 2) educator's pedagogical skill, and 3) educator's attitude towards sustainability. The lecturer participants argued that, to ensure EfS enactment is successful at the university, the teacher/lecturer should have competencies that are required to teach EfS. For example, L6 stated, "It is important for the educator to be knowledgeable" (L6' interview). In the same vein, the students in Focus group 3 also argued that the educator's knowledge is an important factor to ensure successful EfS implementation.

Interviewer. What do you think as an important factor to ensure the EfS implementation is successfur?

Student 3B: The lecturer's knowledge about the topic.

Student $3 \mathrm{~A}: \mathrm{Im}$ always impressed when the lecturer teaches us new knowledge about sustainability.

Student 3D: Yes, like new technology in the field that can be used to solve sustainability problems.

Student 3C: I agree with what you said. When we enroll in the course, we expect to receive new knowledge from the lecturer.

(Focus group 3 interview)

Apart from the educator's knowledge in sustainability topics as an important factor to ensure successful EfS implementation, the participants also argued that the educator's pedagogical skill is one of the important factors for EfS. L5 highlighted that the educator needs to be skilful. She stated:

We need skilful manpower as the driver of EfS in higher education. The educator needs to have the skill to teach sustainability course. The lecturer must not only know how to teach, but also needs to have multidisciplinary skills, i.e. knowing how to integrate different disciplines as the discussion of sustainability involves many disciplines (L5's interview).

In addition, pedagogical skill is also being perceived as an important competency for the teacher to ensure the successful EfS enactment. L6 stated, "The educator must be experienced and know how to teach. They should also have pedagogical skill." (L6' interview). In the same vein, the participating students also argued that educator's pedagogical skill is one of the important factors to ensure successful EfS.

Interviewer. What do you think as an important factor to ensure the EfS implementation is successfur?

Student 1A: The lecturer should know how to attract students interest to learn sustainability.

Students $1 D$ : And, the lecturer should be knowledgeable in the topic.

Students $1 B$ : I love to learn if the lecturer can relate the topic to daily life. So, we can see the connection.

Student 1 C: Yes, the sustainability class should be interesting and not a boring lecture.

(Focus group 1 interview)

The students in Focus group 1 argued that the lecturer's teaching skill is an 
important factor to ensure a successful EfS implementation. Besides the educator's competency to teach EfS, the educator's attitude towards sustainability is perceived as an important factor that determines the success of EfS enactment at the university. L1 stated:

People can teach sustainability. Nevertheless, they need to have deep knowledge and not just superficial knowledge. The most important is that they must have a positive attitude towards sustainability. If they only teach without a passion and right attitude towards the environment, their teaching is meaningless as they cannot relate the sustainability issues by themselves.

(L1's interview).

Furthermore, L6 also argued that the attitude of EfS educator is crucial to ensure the EfS enactment is successful. L6 stated, "One important thing to make EfS successful is that you must have a passionate teacher. If you don't have passionate teachers, you can't do it." (L6' interview). In the same vein, students in Focus group 2 also argued that the educator's attitude towards sustainability is an important factor to ensure a successful EfS implementation.

Interviewer. What do you think as an important factor to ensure the EfS implementation is successfur?

Student 2D: I think, if you want to make EfS successful, the lecturer should walk the talk.

Interviewer. Can you explain it further?

Student 2D. Let say, when the students doing a fieldwork, the lecturer should also go to the field together and show a good example of how to do a fieldwork.

Student 2B: Similarly, if the university runs the sustainability program, the lecturer should participate in such program together with the students.

Student $2 C$ : They need to be a role model to the students.

(Focus group 2 interview)

Focus group 2 consists of post-graduate students, whereas Focus group 1 and Focus group 3 consist of undergraduate students. The students in the Focus group 2 have different opinion concerning the importance of the educator factor for EfS. Students in Focus group 2 argued that the educator's attitude towards sustainability is important, whereas students in Focus groups 1 and 3 argued that the educator's pedagogical skill and knowledge are important. These differences might be attributed to the different levels of the students' study program. In a high power distance society such as Malaysian society, the society perceived the quality of education is dependent on the teachers' excellence rather than students' excellence. The reason is that the teacher in Malaysia is considered as a "guru", who develops and plans the intellectual path and initiates learning in a classroom (Manikutty et al., 2007).

\section{Discussion}

Local and institutional systems structures have direct interaction with EfS and curriculum and pedagogy in this study. Meanwhile, global EfS system structures have a weak effect on EfS curriculum and pedagogy. 
The socio-cultural context of the learning, financial constraint, and local sustainability issues are the factors that lecturers considered when they planned their teaching approach for EfS. The lecturer participants acknowledged socio-cultural factors, such as high power distance between students and lecturers, face-saving culture, and conformity that encouraged passiveness in class and deterred students' behavioural engagement and cognitive engagement in EfS learning. In response, the lecturers modified their teaching approach. The modification involved an adaptation to the context. Adaptation is the key characteristic of CAS (Holland, 2006). From a CAS perspective, adaptation usually improves performance and addresses problems. Nevertheless, the findings of this study revealed that the modification of pedagogical approaches was insufficient to transform EfS learning to show the characteristic of Learning III, which required the learner to re-design sustainability principles based on the realisation of the need for paradigm change (Bateson, 1972). This is due to the reason that the modification was a more surface level "change within changelessness" context that did not involve critical reflection on the paradigm (Sterling, 2016).

Despite the students' apparent passiveness in the class, the student participants, in fact, reported a preference for active learning that emphasize hands-on and outdoor learning. While the students acted passively when they were in the classroom according to the norm in the local culture, they preferred active learning in the field instead of didactic learning in the classroom. Nevertheless, the exposure to other learning methods, such as active learning, has some influence on the students' preferences of teaching approach. According to Wong (2004), cultural norms can be transcended when students focus on contextual relevance, such as their perception of the course requirements.

In conjunction with socio-cultural influences on EfS teaching and learning, local sustainability issues also influence EfS teaching and learning at the university. Local sustainability issues influence EfS teaching in two ways: 1) the lecturers perceived local sustainability issues as a stimulus for them to teach EfS, and 2) the lecturers utilised local sustainability issues as learning and teaching medium. The local sustainability issues have potential to create relevance for the students as the issues are connected to the students (Hart, 2016).

Global sustainability agendas were included in certain topics of EfS curriculum at the university. Nevertheless, the global sustainability agenda constituted less than $10 \%$ of the overall content. Thus, limited exposure to the global sustainability issues may contribute to the limited knowledge of global sustainability issues among the student participants in this study. In addition, global influence was not obvious in EfS pedagogical approach in this study. This is due to the reason that the lecturer participants preferred to use local sustainability issues as the examples and case study in their teaching instead of global sustainability issues. According to the participants, despite the global sustainability agenda had the impacts on some sustainability practices in Malaysia, it did not impact much on education. From a CAS perspective, the agents (i.e. lecturer and student) in a 
system reacted differently to different stimuli in the environment (Holland, 2006). In this case, the stimuli were local sustainability issues and global sustainability agenda. The process of interaction between agents in a system and its environment involved selection. The selection is required as the agents have to recognise which phenomena, out of a range, are to be responded to. On the other hand, global sustainability agenda plays a vital role in the university sustainability policy and sustainability enactment at the university level. These findings revealed that global sustainability agenda has a different impact on EfS at the university level, and at the students and lecturers level.

\section{Conclusion}

This study identified socio-cultural factors that influence EfS learning and teaching. Factors, such as high power distance, face saving culture and conformity, became a challenge for a transformative EfS learning and teaching. These socio-cultural factors discourage student's critical questioning of the dominant thinking and culture that govern human behavior. This study also identified that the lecturers attempt to overcome these socio-cultural challenges in EfS teaching, through modification of their pedagogical approaches. This finding provides a leverage point to optimize the learning while at the same time acknowledging these socio-cultural challenges in Asian university context. Certain EfS curriculum and pedagogical approaches that take into consideration socio-cultural factors are unique in the Malaysian context. Furthermore, certain socio-cultural factors also potentially become barriers to transformative EfS learning at this university.

\section{Acknowledgements}

This study was part of the project Resilient Community in Smart and Sustainable Campus.

\section{Conflicts of Interest}

The authors declare no conflicts of interest regarding the publication of this paper.

\section{References}

Abdulrazak, S. R., \& Ahmad, F. S. (2014). Sustainable Development: A Malaysian Perspective. Procedia-Social and Behavioral Sciences, 164, 237-241. https://doi.org/10.1016/j.sbspro.2014.11.072

Bacon, C. M., Mulvaney, D., Ball, T. B., DuPuis, E. M., Gliessman, S. R., Lipschutz, R. D., \& Shakouri, A. (2011). The Creation of an Integrated Sustainability Curriculum and Student Praxis Projects. International Journal of Sustainability in Higher Education, 12, 193-208. https://doi.org/10.1108/14676371111118237

Barth, M. (2013). Many Roads Lead to Sustainability: A Process-Oriented Analysis of Change in Higher Education. International Journal of Sustainability in Higher Education, 14, 160-175. https://doi.org/10.1108/14676371311312879 
Bateson, G. (1972). Steps to an Ecology of Mind. London: Jason Aronson Inc. http://www.edtechpost.ca/readings/GregoryBateson-Ecology of Mind.pdf

Darus, Z. M., Rashid, A. K. A, Hashim, N., Omar, Z., Sauru, M., \& Mohammad, N. (2009). Development of Sustainable Campus: Universiti Kebangsaan Malaysia Planning and Strategy. WSEAS Transaction on Environment and Strategy, 5, 273.

Dawe, G., Jucker, R., \& Martin, S. (2005). Sustainable Development in Higher Education: Current Practice and Future Developments. New York: The Higher Education Academy.

Derahim, N., Hashim, H. S., Ali, N., \& Derahim, N. (2011). The Level of Sustainability among Students of Universiti Kebangsaan Malaysia towards Sustainability Campus. Jurnal Personalia Pelajar, 273, 1-10.

Elfithri, R., Mokhtar, M. B., Ismail, S. M., Bin, S., Ezlin, N., Basri, A. et al. (2017). A Decade of Sustainable Campus Programme in Universiti Kebangsaan Malaysia: 2007-2017. In The 6th International Conference on Social Sciences and Humanities (Vol. 2020). Bangi.

Er Ah Choi, N. A. B., Roshafida Hussin, L. H. Z., Azrul Abdul Wahab, F. L. M., Fahm, S. Z. A., Shariffuddin, A. F. A., \& Bakar, M. S. A. (2017). Inisiatif kelestarian kampus: Tahap pengetahuan, kesedaran dan amalan lestari di kalangan kakitangan dan pelajar di Universiti Kebangsaan Malaysia. Journal of Global Business and Social Entrepreneurship, 3, 65-73.

Faruqi, Y. M. (2007). Islamic View of Nature and Values : Could These Be the Answer to Building Bridges between Modern Science and Islamic Science. International Education Journal, 8, 461-469.

Hart, P. (2016). Environmental Education and Science Education. In R. Gunstone (Ed.), Encyclopedia of Science Education (pp. 384-391). New York: Springer.

Hoffstaedter, G. (2011). Modern Muslim Identities: Negotiating Religion and Ethnicity in Malaysia. Copenhagen: Nias Press.

Hofstede Insight. (2017). Countries Comparison Tools. https://www.hofstede-insights.com/product/compare-countries/

Holland, J. (1992). Complex Adaptive Systems. Deadalus, 121, 17-30.

Holland, J. (2006). Studying Complex Adaptive Systems. Journal System Science \& Complexity, 19, 1-8. https://doi.org/10.1007/s11424-006-0001-z

Huckle, J., \& Sterling, S. (1996). Education for Sustainability. London: Earthscan.

Karwowski, W. (2012). A Review of Human Factors Challenges of Complex Adaptive Systems: Discovering and Understanding Chaos in Human Performance. Human Factors, 54, 983-995. https://doi.org/10.1177/0018720812467459

Lattuca, L. R., \& Stark, J. S. (2009). Shaping the College Curriculum: Academic Plans in Context (2nd Ed). San Francisco, CA: Jossey-Bass Inc.

Malaysia, G. (1996). Seventh Malaysia Plan 1996-2000. Kuala Lumpur: Percetakan Nasional.

Manikutty, S., Anuradha, N. S., \& Hansen, K. (2007). Does Culture Influence Learning Styles in Higher Education? International Journal of Learning and Change, 2, 70-87. https://doi.org/10.1504/IJLC.2007.014896

Moore, J. (2005). Is Higher Education Ready for Transformative Learning?: A Question Explored in the Study of Sustainability. Journal of Transformative Education, 3, 76-91. https://doi.org/10.1177/1541344604270862

Omar, Z., Saruwono, M., Mohammad, N., Darus, Z. M., Rashid, A. K. A., \& Hashim, N. 
A. (2009). Development of Sustainable Campus: Universiti Kebangsaan Malaysia Planning and Strategy. WSEAS Transactions on Environment and Development, 5, 273-282.

Pappas, E. (2012). A New Systems Approach to Sustainability: University Responsibility for Teaching Sustainability in Contexts. Journal of Sustainable Education, 3, 1-21.

Redman, E. (2013). Development, Implementation and Evaluation of Sustainability Education through the Integration of Behavioral Sciences into Pedagogy and Practice. Tempe, AZ: Arizona State University.

Rowe, D. (2002). Environmental Literacy and Sustainability as Core Requirements: Success Stories and Model. In W. L. Filho (Ed.), Teaching Sustainability at Universities (pp. 79-103). New York: Peter Lang.

Segalàs, J., Ferrer-Balas, D., Svanström, M., Lundqvist, U., \& Mulder, K. F. (2009). What Has to Be Learnt for Sustainability? A Comparison of Bachelor Engineering Education Competences at Three European Universities. Sustainability Science, 4, 17-27. https://doi.org/10.1007/s11625-009-0068-2

Sipos, Y., Battisti, B., \& Grimm, K. (2008). Achieving Transformative Sustainability Learning: Engaging Head, Hands and Heart. International Journal of Sustainability in Higher Education, 9, 68-86. https://doi.org/10.1108/14676370810842193

Sterling, S. (2004). Higher Education, Sustainability and the Role of Systemic Learning. In P. B. Corcoran, \& A. E. J. Wals (Eds.), Higher Education and the Challenge of Sustainability: Problematics, Promise and Practice (pp. 49-70). Dordrecht: Kluwer Academic.

Sterling, S. (2016). A Commentary on Education and Sustainable Development Goals. Journal of Education for Sustainable Development, 10, 208-213. http://doi.org/10.1177/0973408216661886

Sterling, S., \& Thomas, I. (2006). Education for Sustainability: The Role of Capabilities in Guiding University Curricula. International Journal of Innovation and Sustainable Development, 1, 349-370. https://doi.org/10.1504/IJISD.2006.013735

Stratton, J. (2015). Critical Thinking for College Students. New York: Rowman and Littlefield.

Sulaiman, A. (2013). Sensitive Truths in Malaysia: A Critical Appraisal of the Malay Problem. Peta: Strategic.

Sydow, B. C. (2012). Sustainability Design in Higher Education: Curriculum, Teaching Methods and Program Integration. Doctoral Dissertation, University of South Dakota. http://search.proquest.com.ezproxy.library.uq.edu.au/pqdtglobal/docview/1022030028/ FFEB042A5F6D46ACPQ/1?accountid $=14723$

UCLG. (2011). Culture : Fourth Pillar of Sustainable Development. Barcelona.

UNESCO (2017). Education for Sustainable Development Goals: Learning Objectives.

Wiek, A., Withycombe, L., \& Redman, C. L. (2011). Key Competencies in Sustainability: A Reference Framework for Academic Program Development. Sustainability Science, 6, 203-218. https://doi.org/10.1007/s11625-011-0132-6 